\title{
Improvement in Corrosion Inhibition Efficiency of Molybdate-Based Inhibitors via Addition of Nitroethane and Zinc in Stimulated Cooling Water
}

\author{
Saeed Mohammadi, Fatemeh Baghaei Ravari, and Athareh Dadgarinezhad \\ Department of Materials Science and Engineering, Faculty of Engineering, Shahid Bahonar University, \\ Kerman 7618868366, Iran \\ Correspondence should be addressed to Saeed Mohammadi, s_mohammadi@alumni.ut.ac.ir
}

Received 10 November 2012; Accepted 29 November 2012

Academic Editors: S. Caporali and S. Mabbutt

Copyright ( $) 2012$ Saeed Mohammadi et al. This is an open access article distributed under the Creative Commons Attribution License, which permits unrestricted use, distribution, and reproduction in any medium, provided the original work is properly cited.

\begin{abstract}
An investigation was conducted to improve the corrosion inhibition efficiency of molybdate-based inhibitors for mild steel which is the main construction material of cooling water systems, using nitroethane as an organic compound beside zinc. In this study a new molybdate-based inhibitor was introduced with the composition of $60 \mathrm{ppm}$ molybdate, $20 \mathrm{ppm}$ nitrite, $20 \mathrm{ppm}$ nitroethane, and $10 \mathrm{ppm}$ zinc. Inhibition efficiency of molybdate alone and with nitrite, nitroethane, and zinc on the uniform corrosion of mild steel in stimulated cooling water (SCW) was assessed by electrochemical techniques such as potentiodynamic polarization and electrochemical impedance (AC impedance) measurements. Weight loss measurements were made with coupon testing specimens in the room temperature for $48 \mathrm{~h}$. Studies of electron microscopy, including scanning electron microscopy (SEM) photograph and X-ray energy dispersive spectrometry (EDS) microanalysis, were used. The results obtained from the polarization and $\mathrm{AC}$ impedance curves were in agreement with those from the corrosion weight loss results. The results indicate that the new inhibitor is as effective as molybdate alone, though at one-ninth of the concentration range of molybdate, which is economically favorable.
\end{abstract}

\section{Introduction}

The protection of cooling water systems as well as heat supply water has become one of the great important issues in the world economy. The application of corrosion inhibitors especially in closed systems holds a prominent place amongst other methods of corrosion control [1]. The actual trends in the environmental protection essentially have changed the traditional approach to corrosion inhibition. Since the toxicity of chromate-based inhibitor is a limiting factor in its use as a corrosion inhibitor, the changes in formulation of corrosion inhibitors are prompted primarily by an increasing demand to reduce environmental impact [2]. Molybdatebased inhibitor has long been known as an inorganic and anodic type of corrosion inhibitor, which is effective for protecting mild steel in the $\mathrm{pH}$ range 5.8-8.5 [3, 4]. Lizlovs has observed that in the aqueous system containing aggressive ions, molybdate has corrosion inhibition only in the presence of oxygen [5]. In fact, the presence of aggressive ions such as chloride $\left(\mathrm{Cl}^{-}\right)$and sulfate $\left(\mathrm{SO}_{4}{ }^{-2}\right)$ anions reduces the efficiency of $\mathrm{MoO}_{4}{ }^{2-}$, so higher concentrations are necessary for corrosion inhibition [6,7], which is not economically favorable. In order to achieve better efficiency and reduce the quantity of molybdate, other oxidizing agents such as nitrite $\left(\mathrm{NO}_{2}{ }^{-}\right)$and organic compounds have been employed. Recently, the best method to improve inhibitive capability is using inhibitors in combination with others [8-11]. As it has been observed previously, organic inhibitors usually designated as a film forming protect the metal by forming a hydrophobic film on the metal surface. Therefore, natural organic molecules containing one pair of electrons or associated with multiple specially triple bonds or organic rings can bond to metal surface by electron transfer to the metal to form a coordinate type of link, 
<smiles>CC[N+](=O)[O-]</smiles>

FIGURE 1: Molecular structure of sodium nitroethane.

TABLE 1: Chemical composition of test specimen.

\begin{tabular}{lcccc}
\hline Element & $\mathrm{C}$ & $\mathrm{Si}$ & $\mathrm{Mn}$ & $\mathrm{Fe}$ \\
Test specimen & 0.05 & 0.49 & 0.54 & 98.92 \\
\hline
\end{tabular}

which ultimately produces a barrier to the dissolution of the metal in the electrolyte [12]. As nitroethane contains a carbon chain together with oxidizing agent $\left(\mathrm{NO}_{2}{ }^{-}\right)$, it is predicted that it can improve inhibition efficiency as an organic compound. In addition, Jefferies and Bucher recently studied the addition of zinc as cathodic inhibitor to improve the corrosion inhibition behavior of molybdatebased inhibitors [13]. As a result, it is worth investigating the corrosion inhibition of mild steel in stimulated cooling water (SCW) by using new developed inhibitor containing molybdate, nitrite, nitroethane, and zinc.

\section{Experimental Procedures}

Coupon testing specimens with the dimensions of 5,2 , and $0.3 \mathrm{~cm}$ were used for weight loss measurements. The composition of mild steel specimens is shown in Table 1.

Mild steel of the same alloy composition with an exposed area of $1 \mathrm{~cm}^{2}$ was embedded in epoxy resin and used for electrochemical measurements. Tafel polarization measurements were carried out at open circuit potential $\left(E_{\text {ocp }}\right)$, potentiostat/galvanostat (Princeton Applied Research EG \& G Model $263 \mathrm{~A}$ ), using counter electrode (Pt) and a saturated calomel electrode (SCE) as reference electrode. All the quoted potentials are referred to this reference electrode. The potentiodynamic current-potential curves were carried out at a scan rate $1 \mathrm{mV} / \mathrm{sec}$. For impedance measurement, the same equipment was used for the Tafel polarization measurement and combined with frequency response analyzer (Princeton Model 1020). The impedance measurement was carried out using AC signals of amplitude $10 \mathrm{mV}$ peak to peak at the open circuit potential in the frequency range $100 \mathrm{KHz}$ to $10 \mathrm{mHz}$. Before each test, the specimens were prepared with silicon carbide paper 220-1200 grit, degreased in acetone, and washed in distilled water. Test solutions with different inhibitors (Table 2) were prepared by dissolving analytical grade sodium molybdate $\left(\mathrm{Na}_{2} \mathrm{MoO}_{4}\right)$, sodium nitrite $\left(\mathrm{NaNO}_{2}\right)$, zinc sulfate $\left(\mathrm{ZnSO}_{4}\right)$, and sodium nitroethane $\left(\mathrm{C}_{2} \mathrm{H}_{5} \mathrm{NNaO}_{2}\right)$.

Figure 1 shows the molecular structure of sodium nitroethane. Distilled water with $500 \mathrm{ppm}$ sodium chloride, $520 \mathrm{ppm}$ sodium sulfate, $170 \mathrm{ppm}$ sodium bicarbonate, and $25 \mathrm{ppm}$ sodium carbonate was used as SCW [14].
TABLE 2: Chemical composition of inhibitors.

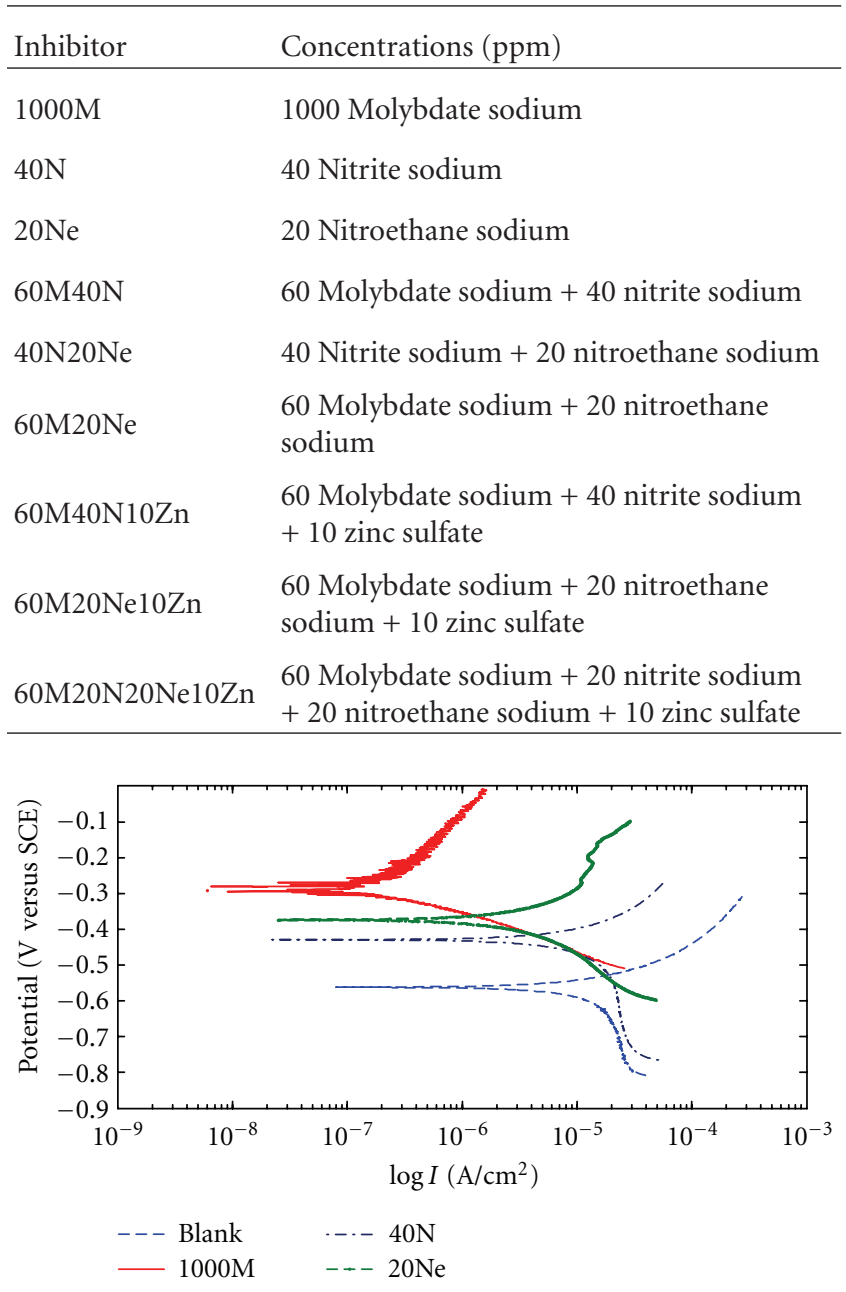

FIGURE 2: Polarization curves for mild steel in SCW without inhibitor and with inhibitor $1000 \mathrm{ppm}$ molybdate, $40 \mathrm{ppm}$ nitrite, and $20 \mathrm{ppm}$ nitroethane.

All tests were performed at neutral $\mathrm{pH}$ and room temperature. Before measurements of polarization curves, a stabilization period of $20 \mathrm{~min}$ was observed which proved sufficient as indicated by open circuit potential $\left(E_{\text {ocp }}\right)$. Table 2 shows the composition of different inhibitors used in this work.

The surface morphology of the mild steel samples after immersion in SCW without inhibitor and with inhibitor $1000 \mathrm{M}$ and the new optimized inhibitor was photographed using SEM and was analyzed by EDS (Cam Scan 2300 MV).

\section{Results and Discussion}

3.1. Polarization Curves. The anodic and cathodic polarization curves for mild steel in SCW without inhibitor and with different inhibitors are shown in Figures 2-5. Figure 2 shows polarization curves for mild steel without inhibitor and with inhibitor $1000 \mathrm{ppm}$ molybdate, $40 \mathrm{ppm}$ nitrite, and $20 \mathrm{ppm}$ nitroethane. 
TABLE 3: Electrochemical polarization parameters for mild steel in SCW without inhibitor and with different inhibitors.

\begin{tabular}{|c|c|c|c|c|c|}
\hline Inhibitor & $E_{\text {corr }}(\mathrm{mV})$ & $\beta c(\mathrm{mV} / \mathrm{dcade})$ & $\beta \mathrm{a}(\mathrm{mV} / \mathrm{dcade})$ & $I_{\text {corr }}\left(\mu \mathrm{A} / \mathrm{cm}^{2}\right)$ & $\eta(\%)$ \\
\hline Blank & -550 & 135 & 325 & 14.5 & - \\
\hline $1000 \mathrm{M}$ & -285 & 78 & 187 & 0.186 & 98.6 \\
\hline $40 \mathrm{~N}$ & -471 & 154 & 188 & 5.6 & 61.4 \\
\hline $20 \mathrm{Ne}$ & -380 & 98 & 103 & 1.82 & 87.4 \\
\hline $60 \mathrm{M} 40 \mathrm{~N}$ & -308 & 141 & 137 & 1.63 & 88.7 \\
\hline $40 \mathrm{~N} 20 \mathrm{Ne}$ & -340 & 68 & 74 & 0.83 & 94.3 \\
\hline $60 \mathrm{M} 20 \mathrm{Ne}$ & -330 & 108 & 153 & 0.59 & 96 \\
\hline $60 \mathrm{M} 40 \mathrm{~N} 10 \mathrm{Zn}$ & -318 & 103 & 86 & 0.7 & 95.2 \\
\hline 60M20Ne10Zn & -336 & 79 & 144 & 0.23 & 98.2 \\
\hline $60 \mathrm{M} 20 \mathrm{~N} 20 \mathrm{Ne} 10 \mathrm{Zn}$ & -298 & 90 & 196 & 0.173 & 98.8 \\
\hline
\end{tabular}

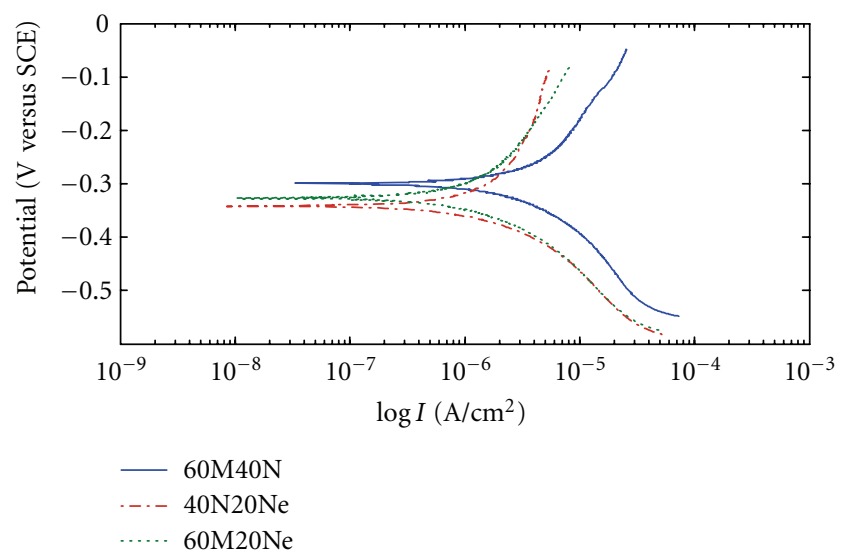

Figure 3: Polarization curves for mild steel exposed to mixture of $60 \mathrm{ppm}$ molybdate and $40 \mathrm{ppm}$ nitrite, $40 \mathrm{ppm}$ nitrite and $20 \mathrm{ppm}$ nitroethane, and $60 \mathrm{ppm}$ molybdate and $20 \mathrm{ppm}$ nitroethane.

The addition of $1000 \mathrm{ppm}$ molybdate, $40 \mathrm{ppm}$ nitrite, and 20 ppm nitroethane shifted the corrosion potentials of the mild steel to more positive values and also decreased the corrosion current densities $\left(I_{\text {corr }}\right)$, indicating that molybdate, nitrite, and nitroethane are anodic inhibitors.

Table 3 gives values of corrosion potentials $\left(E_{\mathrm{corr}}\right)$, corrosion current densities $\left(I_{\text {corr }}\right)$, Tafel slopes $(\beta c$ and $\beta \mathrm{a})$, and inhibition efficiency $(\eta \%)$ obtained from polarization measurements of mild steel for different inhibitors in SCW. The corrosion current densities were obtained from the polarization curves by linear extrapolation of Tafel curves at point of $50 \mathrm{mV}$ more positive and $50 \mathrm{mV}$ more negative than $E_{\text {ocp }}$, respectively.

The inhibition efficiency is defined as

$$
\eta(\%)=\frac{I_{\text {corr }}-I_{\text {corr }(i)}}{I_{\text {corr }}} \times 100,
$$

where $I_{\text {corr }}$ and $I_{\text {corr }(i)}$ are the corrosion current density values without inhibitor and with different inhibitors, respectively.

For the curve $1000 \mathrm{M}$, corrosion current density is $0.185\left(\mu \mathrm{A} / \mathrm{cm}^{2}\right)$, indicating a negligible corrosion rate. But it is not suitable because the concentration is high. According to the obtained results, molybdate was considered as a weak oxidizer, so other oxidizing agents such as nitrite and nitroethane were added to molybdate in order to achieve better efficiency and reduce the quantity of molybdate.

Figure 3 exhibits the polarization curves for mild steel exposed to mixture of $60 \mathrm{ppm}$ molybdate and $40 \mathrm{ppm}$ nitrite, $40 \mathrm{ppm}$ nitrite and $20 \mathrm{ppm}$ nitroethane, and $60 \mathrm{ppm}$ molybdate and 20 ppm nitroethane.

According to the curves $60 \mathrm{M} 40 \mathrm{~N}$, a concentration of $60 \mathrm{ppm} \mathrm{MoO}_{4}{ }^{2-}$ and $40 \mathrm{ppm} \mathrm{NO}_{2}{ }^{-}$appeared to be more efficient than molybdate and nitrite alone at mentioned concentrations [11]. Also by considering curve 40N20Ne, one should point out that in solution containing both nitrite and nitroethane ions, anodic curves were shifted to more positive values compared with nitrite and nitroethane alone, indicating synergistic behavior and improvement in the inhibition efficiency. According to Figure 2, nitroethane with half of the concentration range of nitrite exhibits better inhibition corrosion efficiency. So the combination of $60 \mathrm{ppm}$ molybdate and $20 \mathrm{ppm}$ nitroethane was used in order to achieve better efficiency and reduce the corrosion current densities of Tafel curve 60M40N.

Considering the fact that cathodic inhibitors improve the corrosion inhibition efficiency and reduce the corrosion current densities, combination of zinc with mixture of $60 \mathrm{ppm}$ molybdate and $40 \mathrm{ppm}$ nitrite and mixture of $60 \mathrm{ppm}$ molybdate and $20 \mathrm{ppm}$ nitroethane was used to improve the corrosion inhibition efficiency of Tafel curves $60 \mathrm{M} 40 \mathrm{~N}$ and $60 \mathrm{M} 20 \mathrm{Ne}$, as shown in Figure 4.

According to the Tafel curves $60 \mathrm{M} 40 \mathrm{~N} 10 \mathrm{Zn}$ and $60 \mathrm{M} 20 \mathrm{Ne} 10 \mathrm{Zn}$, addition of zinc (with delay to cathodic reactions) to oxidizing agents such as molybdate, nitrite, and nitroethane improves the corrosion inhibition efficiency and reduce the corrosion current densities of mild steel specimens in SCW. Moreover, addition of zinc to Tafel curves $60 \mathrm{M} 40 \mathrm{~N}$ and $40 \mathrm{~N} 20 \mathrm{Ne}$ shifts the cathodic and anodic branches of the Tafel plots to less corrosion current values $\left(I_{\text {corr }}\right)$ at relatively the same corrosion potentials, indicating that zinc acts as cathodic inhibitor besides other anodic inhibitors.

Polarization curves for mild steel were exposed to SCW water by adding molybdate, nitrite, nitroethane, and zinc 


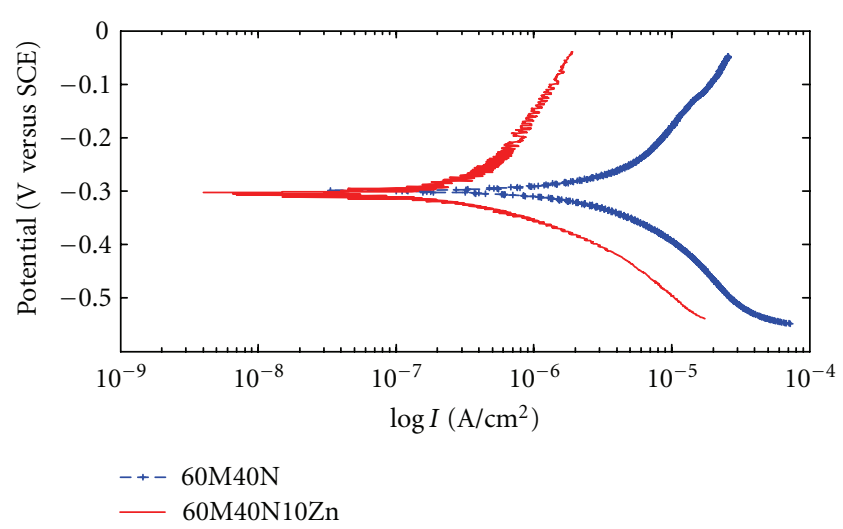

(a)

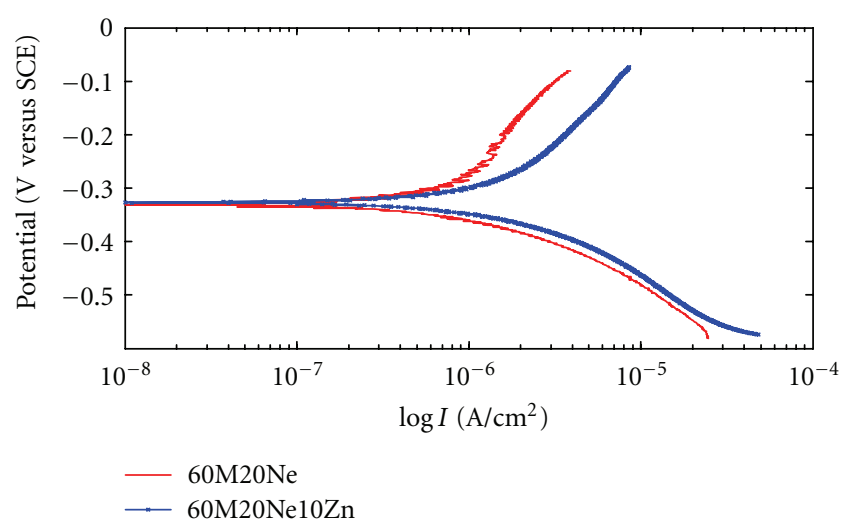

(b)

FIGURE 4: Polarization curves for mild steel in SCW by adding zinc to (a) $60 \mathrm{ppm}$ molybdate and $40 \mathrm{ppm}$ nitrite, curve $60 \mathrm{M} 40 \mathrm{~N} 10 \mathrm{Zn}$ and (b) $40 \mathrm{ppm}$ nitrite and $20 \mathrm{ppm}$ nitroethane, curve $40 \mathrm{~N} 20 \mathrm{Ne} 10 \mathrm{Zn}$.

(60 ppm, 20 ppm, 20 ppm, and 10 ppm, resp.), and 1000 ppm molybdate alone is shown in Figure 5. For comparison polarization curves in SCW and without inhibitor are included.

The suitable combination of $\mathrm{MoO}_{4}{ }^{2-}+\mathrm{NO}_{2}{ }^{-}$beside nitroethane and zinc ions provides the necessary oxidizing environment to support $\mathrm{MoO}_{4}{ }^{2-}$ film formation and synergically lower the corrosion rate. This combination also overcomes the high concentration of $\mathrm{MoO}_{4}{ }^{2-}$, with relatively the same $E_{\text {corr }}$, which is economically favorable. Also for optimized inhibitor current density was on the order of $0.173\left(\mu \mathrm{A} / \mathrm{cm}^{2}\right)$, which was lowered by about $6.9 \%$ compared with $1000 \mathrm{ppm}$ molybdate alone. It can be attributed to the absorption of other ions on the metal in conjunction with $\mathrm{MoO}_{4}{ }^{2-}$ to produce an insoluble compound, providing passivity more readily than $\mathrm{MoO}_{4}{ }^{2-}$ alone [11].

Regarding these results, it can be concluded that the value of corrosion of current density of mild steel in SCW with the addition of molybdate decreases, and with addition of nitrite, nitroethane, and zinc ions to molybdate it decreases more and its inhibition efficiency increases.

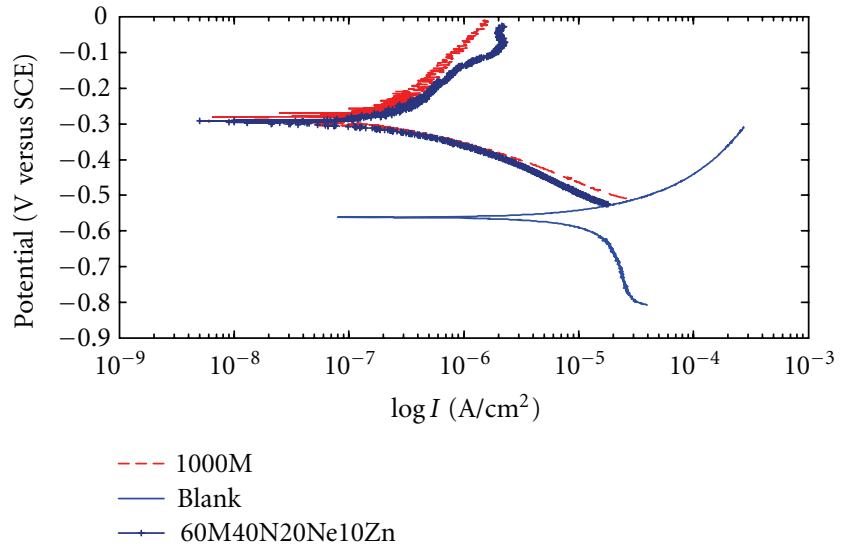

FIGURE 5: Polarization curves for mild steel in SCW without inhibitor and with inhibitor $1000 \mathrm{M}$ and new optimized inhibitor.

TABLE 4: AC impedance parameters for mild steel in SCW without inhibitor and with different inhibitors.

\begin{tabular}{lcc}
\hline Inhibitor & $R_{\mathrm{ct}}\left(\Omega \cdot \mathrm{cm}^{2}\right)$ & $\eta(\%)$ \\
\hline Blank & 1068 & - \\
$1000 \mathrm{M}$ & 16345 & 93.5 \\
$40 \mathrm{~N}$ & 1650 & 56.8 \\
$20 \mathrm{Ne}$ & 4470 & 76.1 \\
$60 \mathrm{M} 40 \mathrm{~N}$ & 4513 & 76.6 \\
$40 \mathrm{~N} 20 \mathrm{Ne}$ & 4518 & 76.8 \\
$60 \mathrm{M} 20 \mathrm{Ne}$ & 7083 & 84.9 \\
$60 \mathrm{M} 40 \mathrm{~N} 10 \mathrm{Zn}$ & 4720 & 77.4 \\
$60 \mathrm{M} 20 \mathrm{Ne} 10 \mathrm{Zn}$ & 7360 & 85.5 \\
$60 \mathrm{M} 20 \mathrm{~N} 20 \mathrm{Ne} 10 \mathrm{Zn}$ & 17205 & 93.8 \\
\hline
\end{tabular}

3.2. AC Impedance Curves. Figures 6 and 7 show the Bode and Bode phase plots of steel electrode without inhibitor and with different inhibitors. The main effect of different inhibitors is an increase in the impedance modulus, $|z|$, below $10 \mathrm{mHz}$ (an increase in polarization resistance $\left(R_{p}\right)$ ) and also a higher phase angle.

In Bode phase plots, only one peak is in the phase angle $(\alpha)$ versus frequency $(f)$ plot, indicating that there is only one time constant (a single relaxation time constant).

Figure 8 shows Nyquist plots for the steel electrode in SCW solutions without inhibitor and with different inhibitors. The impedance loops measurements were depressed semicircles with their center below the axis. This phenomenon is known as the dispersing effect [15]. In Nyquist plots, the corrosion resistance of each of the samples was determined by $R_{p} . R_{p}$ is given by [16]

$$
R_{p}=\lim _{\omega \rightarrow 0} R_{e}\left\{Z_{f}\right\}_{E=E_{\text {corr }}},
$$

where $R_{e}\left\{Z_{f}\right\}$ represents the real part of the complex faradic impedance, $Z_{f}$ and $\omega$ correspond to the angular velocity of the AC signal ( $\omega=2 \pi f$, where $f$ is frequency, $(\mathrm{Hz})) . R_{p}$ values were obtained by fitting the experimental Nyquist data to a simple semicircle and extrapolating to $Z_{\mathrm{im}}=0$. 


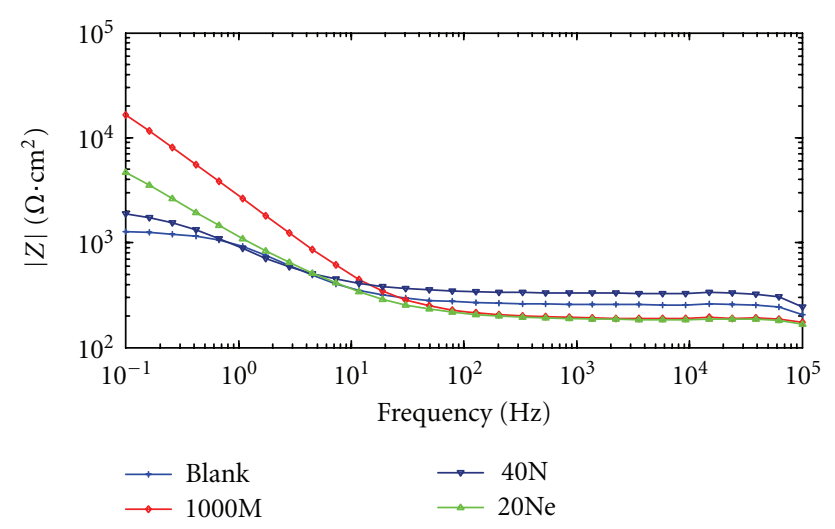

(a)

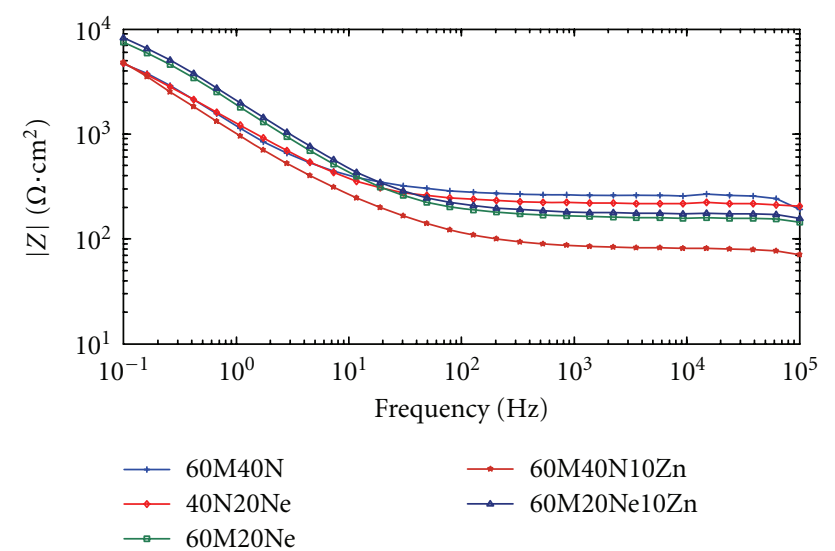

(b)

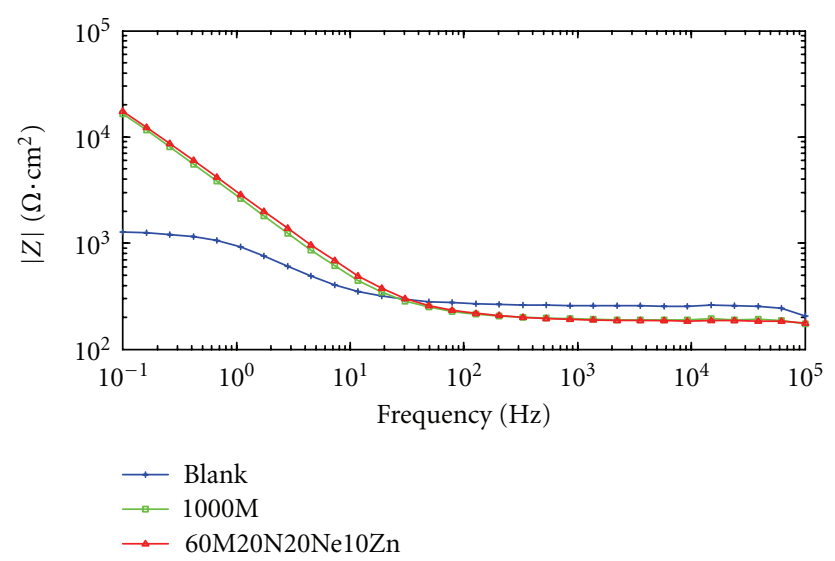

(c)

Figure 6: Bode plots for mild steel in SCW solution (a) without inhibitor and with different inhibitor.

By considering AC impedance curves, it was found that polarization resistance increases in the following order.

BLANK $<40 \mathrm{~N}<20 \mathrm{Ne}<40 \mathrm{~N} 20 \mathrm{Ne} \approx 60 \mathrm{M} 40 \mathrm{~N}<$ $60 \mathrm{M} 40 \mathrm{~N} 10 \mathrm{Zn}<60 \mathrm{M} 20 \mathrm{Ne}<60 \mathrm{M} 20 \mathrm{Ne} 10 \mathrm{Zn}<1000 \mathrm{M} \leq$ $60 \mathrm{M} 20 \mathrm{~N} 20 \mathrm{Ne} 10 \mathrm{Zn}$.

Table 4 gives the values of inhibition efficiency $(\eta \%)$ and polarization resistance $\left(R_{\mathrm{ct}}\right)$ obtained from the $\mathrm{AC}$

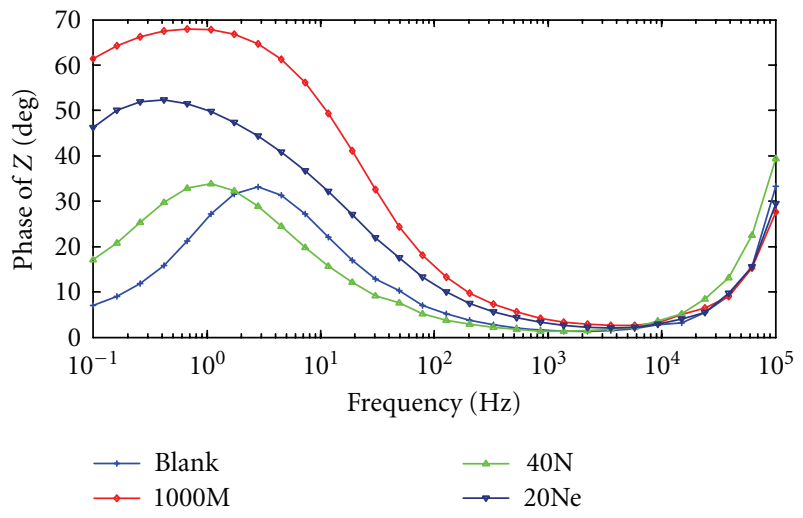

(a)

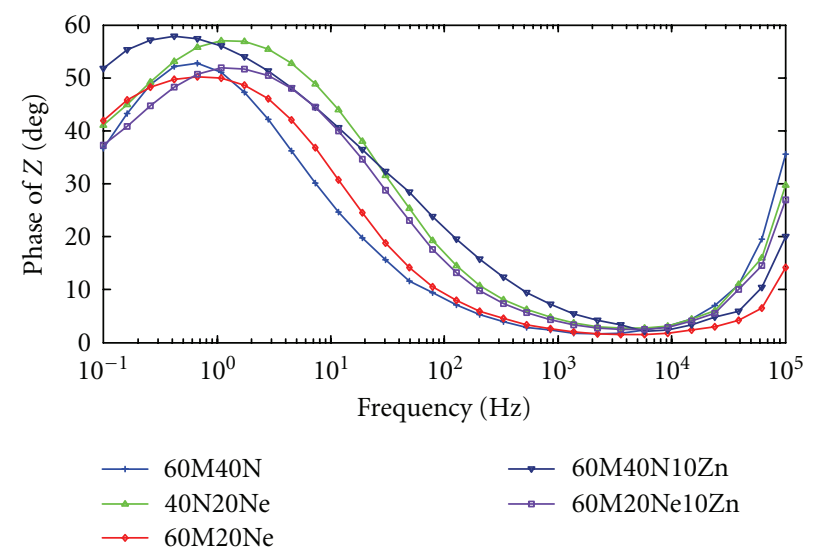

(b)

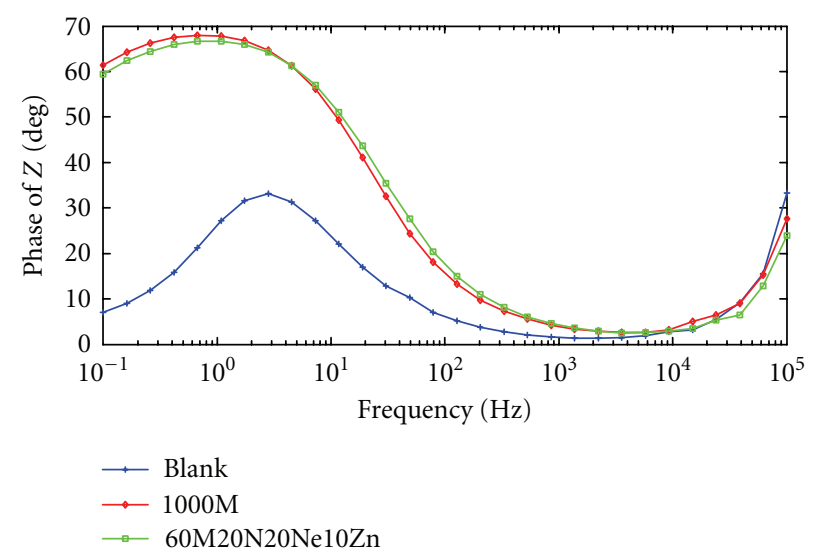

(c)

FIGURE 7: Bode phase plots for mild steel in SCW solution without inhibitor and with inhibitor.

impedance measurements. The inhibition efficiency is defined as

$$
\eta(\%)=\frac{R_{\mathrm{ct}(i)}-R_{\mathrm{ct}}}{R_{\mathrm{ct}(i)}} \times 100,
$$

where $R_{\mathrm{ct}}$ and $R_{\mathrm{ct}(i)}$ are the polarization resistance without inhibitor and with different inhibitors, respectively. 


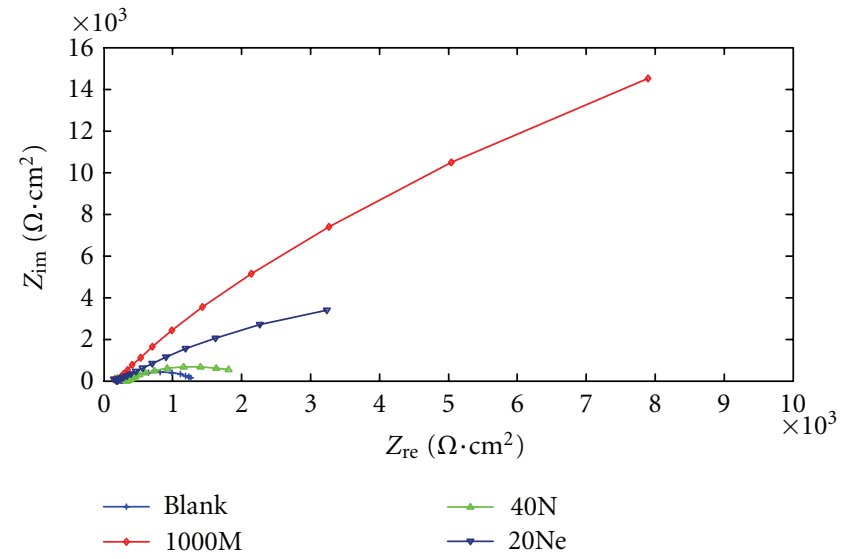

(a)

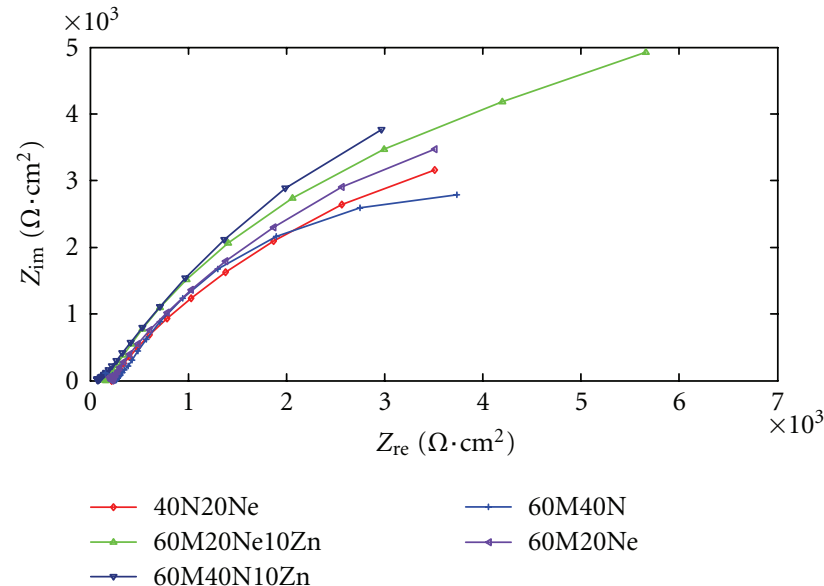

(b)

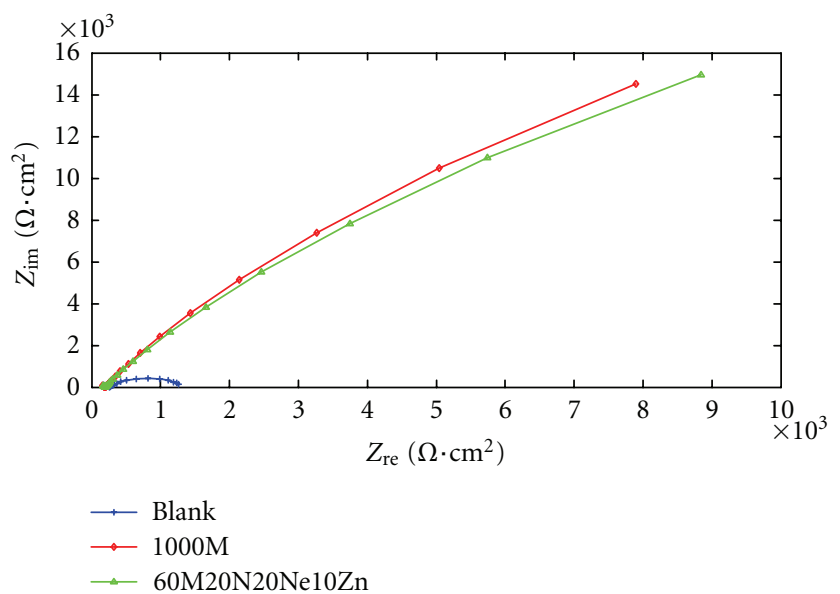

(c)

FIGURE 8: Nyquist plots for mild steel in SCW solution without inhibitor and with inhibitor.

TABLE 5: Weight loss measurements for mild steel in SCW without inhibitor and with different inhibitors.

\begin{tabular}{lc}
\hline Inhibitor & $\eta(\%)$ \\
\hline Blank & - \\
$1000 \mathrm{M}$ & 86.5 \\
$40 \mathrm{~N}$ & 49.7 \\
$20 \mathrm{Ne}$ & 69.2 \\
$60 \mathrm{M} 40 \mathrm{~N}$ & 70.1 \\
$40 \mathrm{~N} 20 \mathrm{Ne}$ & 69.8 \\
$60 \mathrm{M} 20 \mathrm{Ne}$ & 78 \\
$60 \mathrm{M} 40 \mathrm{~N} 10 \mathrm{Zn}$ & 70.6 \\
$60 \mathrm{M} 20 \mathrm{Ne} 10 \mathrm{Zn}$ & 78.8 \\
$60 \mathrm{M} 20 \mathrm{~N} 20 \mathrm{Ne} 10 \mathrm{Zn}$ & 86.8 \\
\hline
\end{tabular}

The results of the AC impedance test exhibit a good correlation with data obtained from the polarization curves.

3.3. Weight Loss Measurements. The weight loss of samples after $48 \mathrm{~h}$ exposure to solution SCW without inhibitor and with different inhibitors was measured by coupon testing methods [17]. Regarding experimental weight loss data, inhibition efficiency $(\eta \%)$ was calculated classically as follows:

$$
\eta(\%)=\frac{W_{0}-W_{i}}{W_{0}} \times 100,
$$

where $W_{0}$ and $W_{i}$ are the weight loss observed in the absence and in the presence of inhibitor, respectively. Values of inhibition efficiency for mild steel in SCW without inhibitor and with different inhibitors are summarized in Table 5.

For comparison, the inhibition efficiency of polarization, AC impedance, and weight loss results were summarized in Figure 9. According to Figure 9, the results obtained from the polarization and AC impedance curves are in agreement with those from the corrosion weight loss tests.

\subsection{Results of Surface Analysis Techniques}

3.4.1. SEM Analysis. The presence of corrosion inhibitor could be more clearly investigated by means of surface analysis techniques. SEM micrographs of samples after $48 \mathrm{~h}$ 


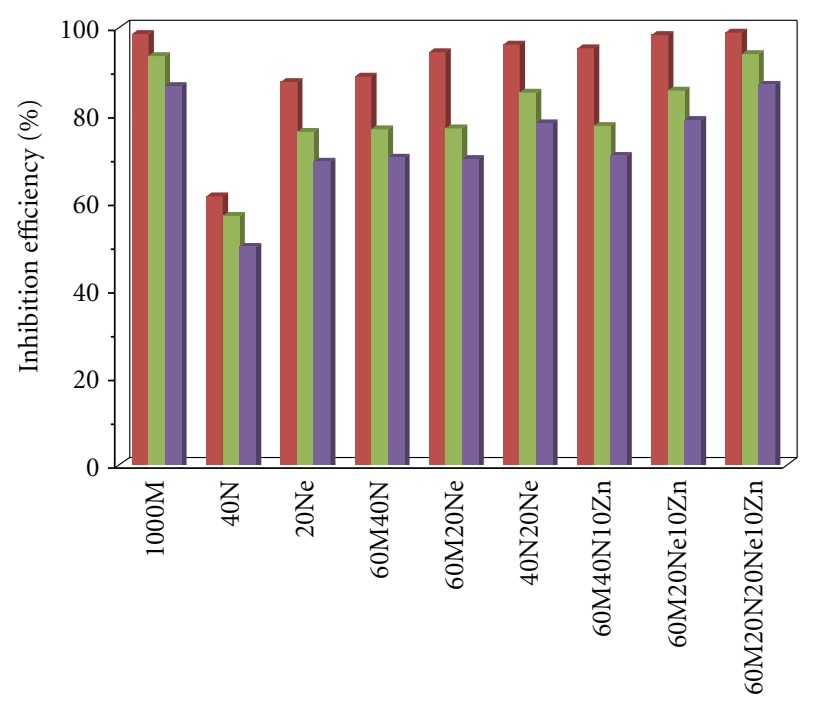

Inhibitor

\footnotetext{
- Polarization

- AC impedance

- Weight loss
}

FIGURE 9: The inhibition efficiency of polarization, AC impedance, and weight loss results for mild steel in SCW with different inhibitors.

exposure to (a) solution SCW without inhibitor, (b) solution SCW with inhibitor $1000 \mathrm{M}$, and (c) solution SCW with new optimized inhibitor are shown in Figure 10. Figures 10 (b) and 10(c) exhibit a layer with uniform, adherent, and continuous structure, while Figure 10(a) shows crystal growth of iron oxide on the surface and its noncontinuous structure. In fact, the decrease in corrosion current densities and increase in polarization resistance when exposed to the previous inhibitors were due to the coverage of metal surface with more protective films [18] as shown in Figure 10. Also the surface roughness of mild steel exposed to solution SCW is much higher than mild steel exposed to solution SCW with the inhibitor $1000 \mathrm{M}$ and optimized inhibitor.

3.4.2. EDS Analysis. EDS analysis of samples after $48 \mathrm{~h}$ exposure to solution SCW without inhibitor and with inhibitor 1000 ppm molybdate and new optimized inhibitor is shown in Figure 11. The presence of $\mathrm{C}, \mathrm{Si}, \mathrm{Mn}$, and Fe element can be observed in all figures. But the presence of Mo is only in Figures $11(\mathrm{~b})$ and $11(\mathrm{c})$, indicating that molybdate oxide is formed on the surface of mild steel sample as stabilizer through its incorporation into the oxide film [18].

In addition, as shown in Figure 11(c), the carbon peak is much higher than (1000 ppm) molybdate alone, indicating that nitroethane ions are adsorbed on the surface besides molybdate ions to improve its inhibition efficiency synergically.

Finally, a glance at the electrochemical (polarization, AC impedance and weight loss method) and surface analysis (SEM photograph and EDS microanalysis) results indicates that new optimized inhibitor has relatively better efficiency

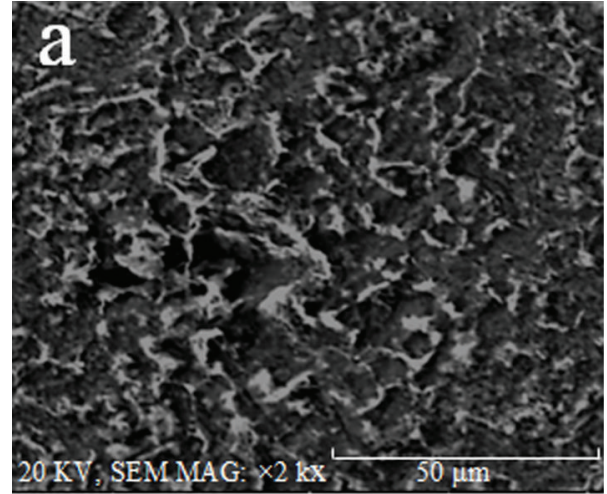

(a)

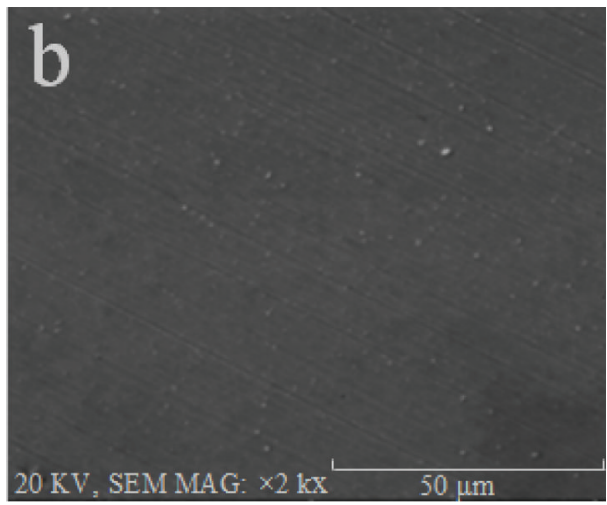

(b)

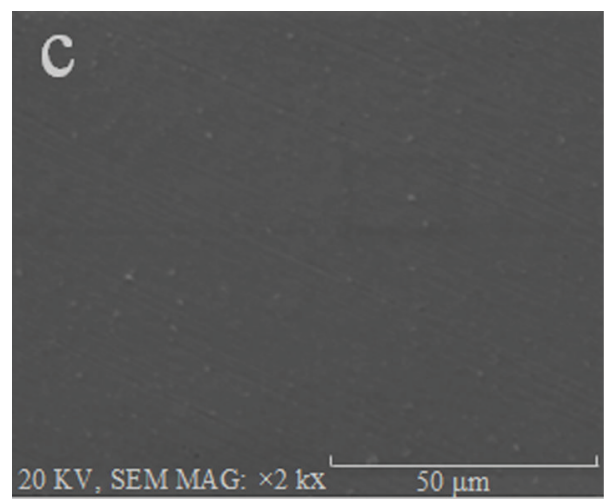

(c)

FIGURE 10: SEM micrograph for mild steel surface (a) in SCW without inhibitor, (b) in SCW with the inhibitor $1000 \mathrm{M}$, and (c) in SCW with new optimized inhibitor.

than $1000 \mathrm{ppm}$ molybdate alone at one ninth of the concentration range of molybdate, which is economically favorable.

\section{Conclusions}

(1) $\mathrm{MoO}_{4}{ }^{2-}$ was proved to be a weak oxidizer, so another oxidizing agents such as $\mathrm{NO}_{2}{ }^{-}$and nitroethane beside cathodic inhibitor zinc were shown to be required to provide adequate protection for mild steel in stimulated cooling water. 


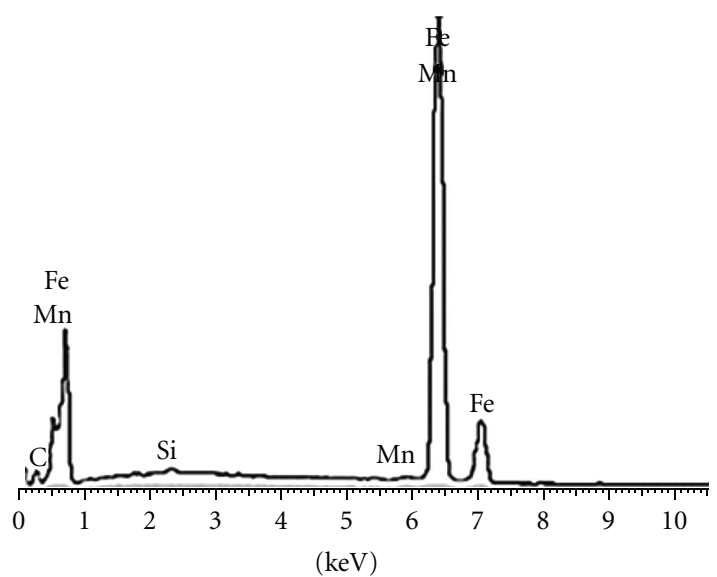

(a)

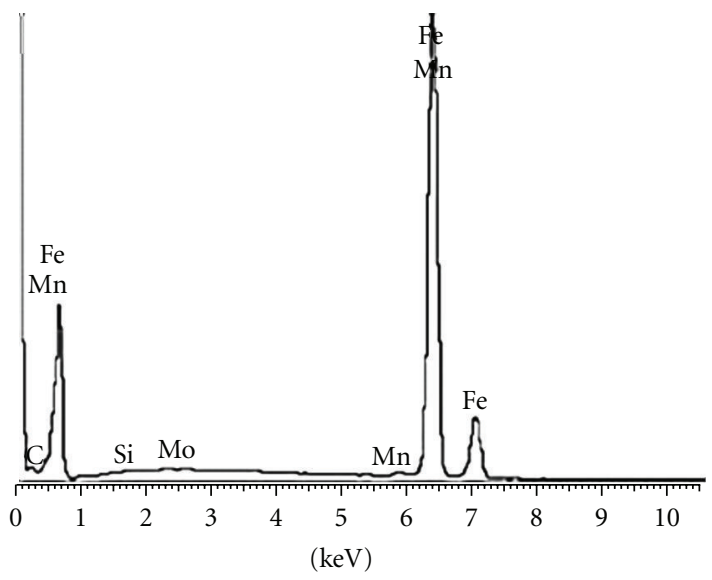

(b)

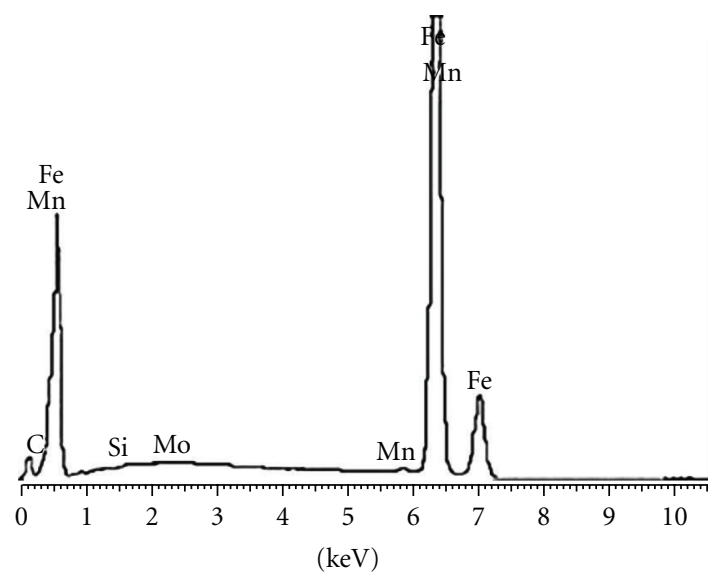

(c)

FIGURE 11: EDS analysis of mild steel (a) in SCW without inhibitor, (b) in SCW with inhibitor $1000 \mathrm{M}$, and (c) in SCW with new optimized inhibitor.

(2) Results obtained from polarization curves showed that new optimized inhibitor with more than 98 percent inhibition efficiency noticeably lowers the corrosion rate of mild steel in stimulated cooling water.
(3) AC impedance curves showed that the combination of molybdate, nitrite, and nitroethane, beside cathodic inhibitor zinc in optimized range can be a suitable replacement for high concentration of 1000 ppm molybdate.

(4) The results of weight loss measurements obtained from coupon testing specimens exhibit a good correlation with data obtained from the polarization and AC impedance curves.

(5) The presence of molybdate as stabilizer of oxide film is observed through the EDS analyzer.

(6) SEM images indicate that new optimized inhibitor could form a relatively steady, compact, and uniform film on the surface of mild steel.

\section{References}

[1] C. M. Mustafa and J. P. G. Farr, "A potentiodynamic study of the corrosion inhibition of mild steel in realistic situation by molybdate and organic compounds containing $-\mathrm{COOH}$ and/or -OH groups," Indian Journal of Technology, vol. 30, p. 424, 1992.

[2] O. Lahodny-Sarc, F. Kapor, and R. Halle, "Corrosion inhibition of carbon steel in chloride solutions by blends of calcium gluconate and sodium benzoate," Materials and Corrosion, vol. 51, no. 3, pp. 147-151, 2000.

[3] Y. J. Qian and S. Turgoose, "Inhibition by zinc-molybdate mixtures of corrosion of mild steel," British Corrosion Journal, vol. 22, no. 4, pp. 268-271, 1987.

[4] M. J. Pryor and M. Cohen, "The inhibition of the corrosion of iron by some anodic inhibitors," Journal of the Electrochemical Society, vol. 100, pp. 203-215, 1953.

[5] E. A. Lizlovs, "Molybdates as corrosion inhibitors in the presence of chlorides," Corrosion, vol. 32, no. 7, pp. 263-266, 1976.

[6] P. A. Burda, "Molybdates as chromate replacement for closed cooling. Water systems in nuclear industry," Corrosion, vol. 92, p. $118,1992$.

[7] M. A. Stranick, "Corrosion inhibition of metals by molybdate. Part I. mild steel," Corrosion, vol. 40, no. 6, pp. 296-302, 1984.

[8] A. J. Bentley, L. G. Earwaker, J. P. G. Farr, and A. M. Seeney, "A technique for the in situ elemental analysis of electrode surfaces," Surface Technology, vol. 23, no. 1, pp. 99-103, 1984.

[9] J. P. G. Farr and M. Saremi, "Molybdate in aqueous corrosion inhibition I: effects of molybdate on the potentiodynamic behaviour of steel and some other metals," Surface Technology, vol. 19, no. 2, pp. 137-144, 1983.

[10] C. M. Mustafa and S. M. S. I. Dulal, "Molybdate and nitrite as corrosion inhibitors for copper-coupled steel in simulated cooling water," Corrosion, vol. 52, no. 1, pp. 16-22, 1996.

[11] D. B. Alexander and A. A. Moccari, "Evaluation of corrosion inhibitors for component cooling water systems," Corrosion, vol. 49, no. 11, pp. 921-928, 1993.

[12] V. S. Sastri, Corrosion Inhibitors. Principles and Applications, John Wiley \& Sons, Toronto, Canada, 1998.

[13] J. Jefferies and B. Bucher, "New look at molybdate," Materials Performance, vol. 31, no. 5, pp. 50-53, 1992.

[14] S. Karim, C. M. Mustafa, M. D. Assaduzzman, and M. Islam, "Effect of nitrate ion on corrosion inhibition of mild steel 
in simulated cooling water," Chemical Engineering Research Bulletin, vol. 14, pp. 87-91, 2010.

[15] F. Mansfeld, M. W. Keding, and S. Tsai, "Recording and analysis of AC impedance data for corrosion studies-experimental approach and results," Corrosion, vol. 38, p. 301, 1982.

[16] W. J. Lorenz and F. Mansfeld, "Determination of corrosion rates by electrochemical DC and AC methods," Corrosion Science, vol. 21, no. 9-10, pp. 647-672, 1981.

[17] ASTM, "Standard practice for laboratory immersion corrosion testing of metal," ASTM International G 31-72, West Conshohocken, Pa, USA, 1990.

[18] S. M. A. Shibli and V. A. Kumary, "Inhibitive effect of calcium gluconate and sodium molybdate on carbon steel," AntiCorrosion Methods and Materials, vol. 51, no. 4, pp. 277-281, 2004. 

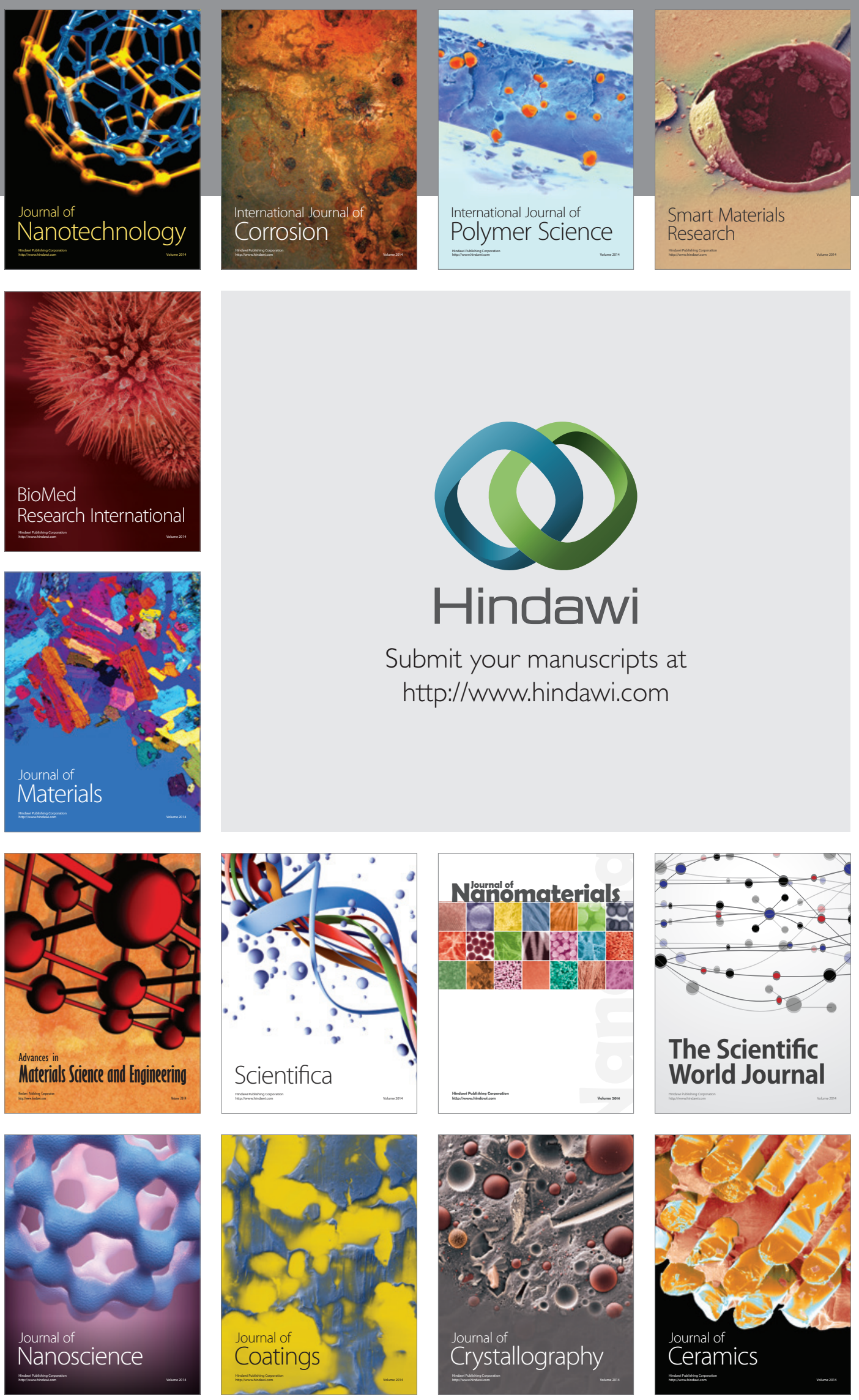

The Scientific World Journal

Submit your manuscripts at

http://www.hindawi.com

\section{World Journal}

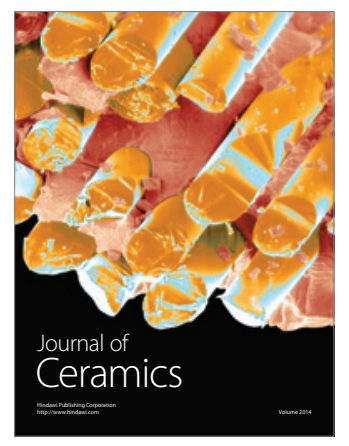

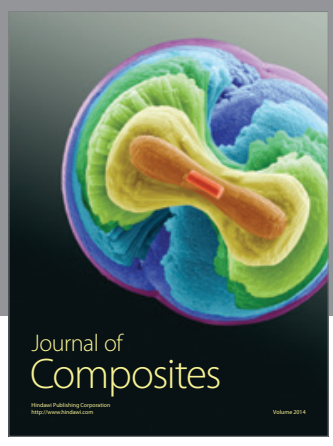
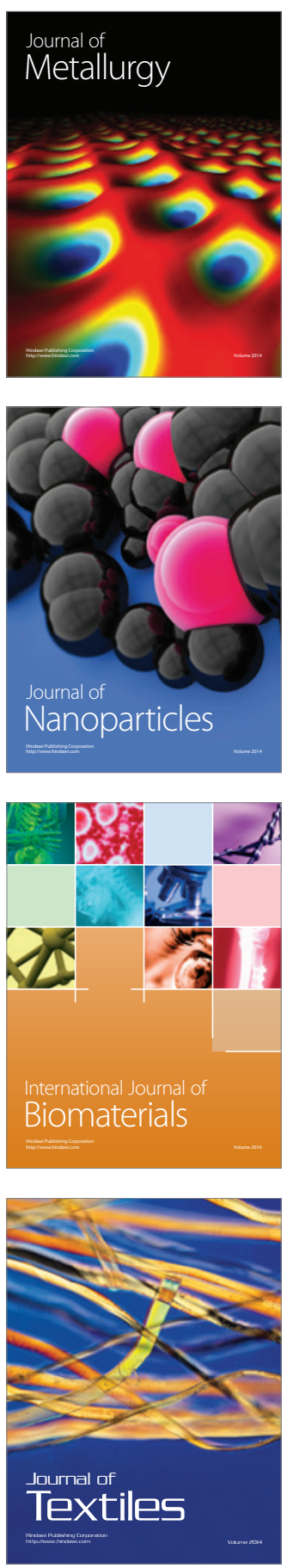